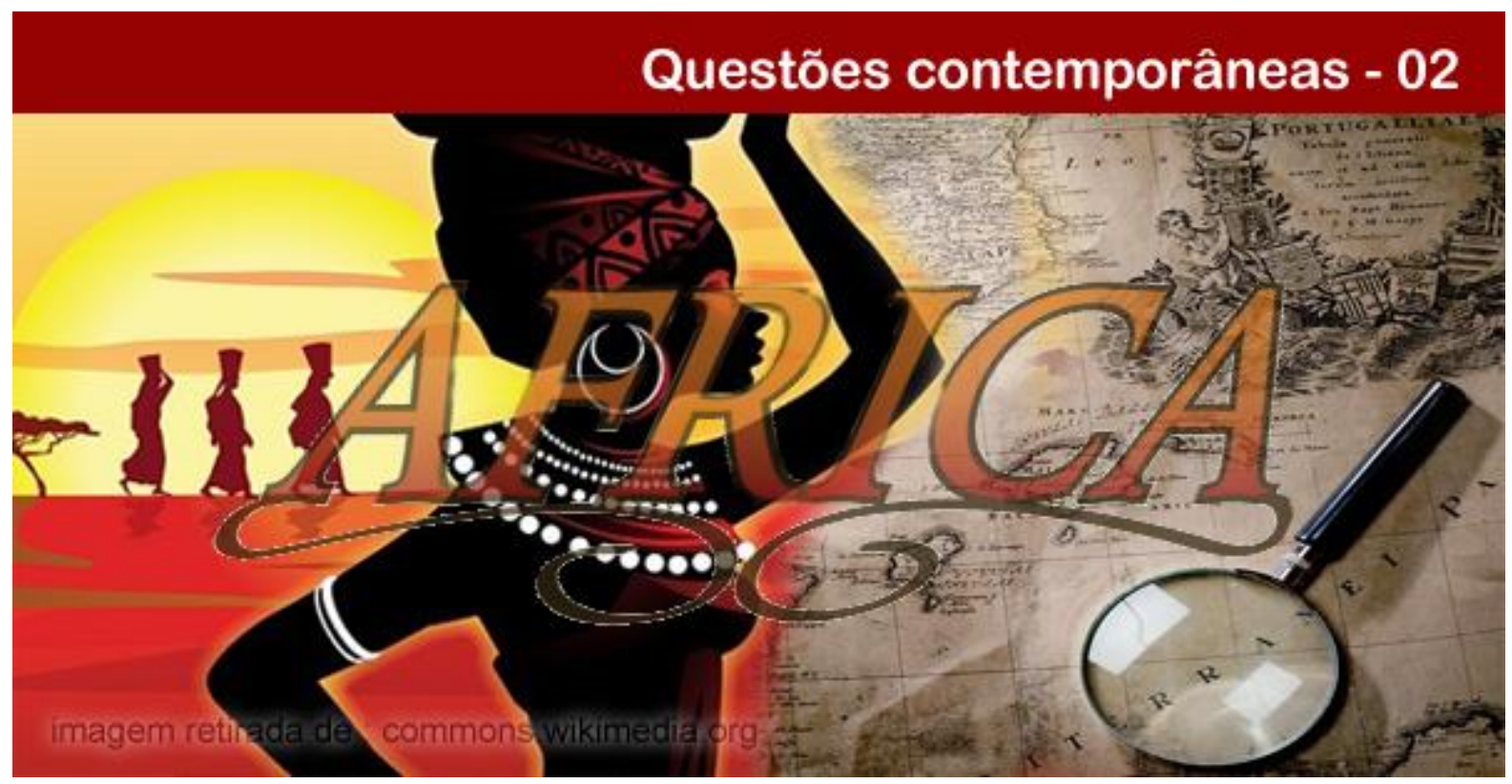

\title{
(RE) PENSANDO O ENSINO DE HISTÓRIA - A ÁFRICA NO CENTRO DO DEBATE
}

\section{Beatriz dos Santos de Oliveira Feitosa}

Professora Assistente no Departamento de História da Universidade Federal de Mato Grosso/UFMT. Doutoranda em História, no Programa de Pós Graduação em História/PPGHIS/UFMT. Pesquisadora no Núcleo de Pesquisa em História da UFMT. E-mail: beatriz-feitosa@uol.com.br.

Resumo: Há um debate que tem tomado conta da academia em torno da problemática resultante da dicotomia entre ensino e pesquisa no campo da história, que leva a uma falsa ideia de que o historiador de ofício não teria relação com o professor de história, que a prática docente no universo da educação básica não manteria em última instância uma relação de reciprocidade com o trabalho de pesquisa desenvolvido na academia. Diante desse debate, este artigo busca um diálogo possível entre o ofício do historiador que passa pela produção e reflexão teórica e a prática docente, entendemos que estas não se constituem em questões dissociáveis, considerando inclusive, que o diálogo que leva a produção de conhecimento nos níveis mais básicos de ensino resultam de um constante diálogo com as pesquisas realizadas no mundo acadêmico, constituindo-se em relatos sistematizados das experiências humanas que deve enriquecer a relação entre professor e educando nas experiências com o conhecimento historicamente produzido. O ensino de história na educação básica, não passa pela formação de pequenos historiadores, não se trata de ensinar teoria histórica para este nível de ensino, tratase tão somente de compreender que na prática de ensino a pesquisa histórica deve fazer parte do cotidiano do professor. O trajeto metodológico proposto pelo artigo deve possibilitar compreender que a História da África é resultante de um trabalho de pesquisa história que se desdobra em ensino de História, cuja disseminação tem o propósito de permitir o melhor conhecimento daquele continente, que traduz a ampliação do conhecimento acerca de nós mesmos, de nossa própria História.

Palavras-chave: Ofício. Historiador. Professor. História da África.

\section{(RE) THINKING THE HISTORY OF EDUCATION - AFRICA IN DEBATE CENTER}

Abstract: There is a debate that has taken hold of academia around the resulting issue of dichotomy between teaching and research in the field of history, which leads to a misconception that the office of historian would have nothing to do with the history teacher, the teaching practice in the world of basic education would not keep ultimately a reciprocal relationship with the research work in the gym. Given this debate, this article seeks a

\section{POLÊM!CA | Revista Eletronica da Uej}


possible dialogue between the office of the historian who goes through the production and theoretical reflection and teaching practice, we understand that these do not constitute severable issues, also considering that the dialogue that leads to the production of knowledge in lower levels of education result from a constant dialogue with the research conducted in the academic world, constituting a systematic reports of human experience that should enrich the relationship between teacher and student in the experiments with the knowledge historically produced. The history of education in basic education, does not go through formation of small historians, it is not to teach historical theory to this level, it is so only to realize that in teaching practice historical research should be part of everyday teacher. The methodological path proposed by the Article should make it possible to understand that African history is the result of a research paper story that unfolds in teaching History, whose dissemination is intended to allow better knowledge of that continent, which reflects the expansion of knowledge about of ourselves, of our own history.

Keywords: Office. Historian. Teacher. History of Africa.

\section{Introdução}

O presente estudo é resultante de uma inquietação vivida durante os anos em que ministrei aulas na Educação Básica, há uma sensação reinante de que o professor (aqui faço referência especialmente ao professor de História) seria um mero reprodutor do conhecimento produzido e que seu trabalho estaria restrito ao universo do ensino, sem nenhuma relação com a pesquisa histórica. No ano de 2013, ao participar de um concurso público cujo tema era a História da África, deparei-me com um objeto de estudo muitas vezes negligenciado no ensino básico por conta da quase inexistência de material didático a respeito, a defesa feita, no texto que segue, é a de que a prática docente é subsidiada pela pesquisa histórica que não deve ser suprimida pela adoção unilateral dos manuais didáticos.

O objetivo deste artigo é tecer reflexões acerca da importância do amadurecimento intelectual na prática cotidiana do professor de história. Considerando que a problematização do passado é a marca do ofício do historiador, faz-se necessário o debate historiográfico que favoreça o diálogo entre os diversos estudiosos que se dedicaram a pesquisas em torno desta problematização, considerando que a construção historiográfica perpassa labirintos de incertezas, questionamentos, ambiguidades e paradoxos que acompanham o pesquisador em seu complexo e muitas vezes solitário ofício, que deve ser entendido também como o ofício do professor de história, é notório que "Para a realização de um projeto educacional, um dos elementos mais importantes do processo é o professor.” (FONSECA, 1995, p. 25).

Tratar-se-á inicialmente da prática de pesquisa e sua relação com a prática docente, dialogando com as produções que tratam da importância do ofício de historiador, para em seguida pensar a relação entre este ofício e a problematização do passado, apresentando finalmente olhares diversos acerca do trabalho com o tempo, na relação temporal passado, presente e futuro, refletindo acerca das contribuições teóricas dadas por autores que 
contribuem para o trabalho com conceitos fundamentais para a historiografia, dentre os quais destaca-se Koselleck (2006), que ao teorizar o conceito de tempo, proporciona que se pense a historicidade da própria História. A opção teórica e metodológica permite que se lance olhares dirigidos à teoria e metodologia que não podem ser entendidos como trabalho apenas do historiador de ofício, pois o professor de história trabalha com conceitos historiográficos no seu cotidiano, o diálogo teórico deve ser entendido como uma possibilidade entre as experiências da sala de aula e o trabalho de pesquisa que não se constituem de forma isolada, mas devem ser entendidos como práticas que convergem.

Parte do texto foi dedicada a reflexões acerca da História da África, no intuito de apontar a importância do conhecimento daquele continente como uma forma de compreender nossa própria História, tecemos considerações sobre a construção de uma imagem do africano feita pelo europeu que culminou em visões de mundo sustentadas no etnocentrismo, primamos ainda por considerações sobre a forma como a produção intelectual europeia do século XIX contribuiu para o fortalecimento de projetos racistas em solo brasileiro, fundamentando inclusive os anos de escravidão neste país. Entendemos que a produção literária se constituiu da importante contribuição no campo da pesquisa histórica por dar visibilidade a experiências dos atores históricos que vivem nos cenários apresentados pela literatura.

É de suma importância manter um diálogo constante entre construção teórica e metodológica que propiciam a compreensão acerca da formação das territorialidades e espacialidades e a prática docente, considerando que a sala de aula é o locus de debate e reflexão acerca das produções resultantes de pesquisas históricas.

\section{Sobre a Relação entre Pesquisa Histórica e Prática Docente}

Ao propor o exercício da pesquisa como fundamental na constituição da prática docente, o que está no foco da discussão é a maneira como a disciplina de História é trabalhada em sala de aula, pretende-se dar visibilidade ao fato de que tal área de conhecimento, bem como as narrativas que a constitui, são resultantes de trabalho de pesquisa. O primeiro volume da obra "História Geral da África", projeto da UNESCO (KIZERBO, 2010) que garantiu que o ponto de vista dos intelectuais africanos sobre a história do seu continente se tornasse algo internacionalmente relevante e acessível aos interessados,

\section{POLÊM!CA | Revista Eletronica da Ueij}


tendo ainda contribuições significativas de ordem local ao ser relançada no Brasil em 2010, com grande facilidade de acesso online, traduz o trabalho de pesquisa realizado por um conjunto de intelectuais africanos, cuja maior contribuição está no trabalho com as discussões epistemológicas e teórico-metodológicas da história da África, tendo por foco a principal obra deste campo do conhecimento até hoje: a História Geral da África (HGA). "Uma obra de oito volumes, com uma média de cerca de 900 páginas por volume, escrita por trezentos e cinquenta especialistas internacionais em história da África”. (BARBOSA, 2012, p. 01).

Neste sentido, não se intenta que as aulas de História promovam a formação de pequenos historiadores, os conteúdos bem como os procedimentos de ensino adotados por cada professor no universo de saberes que são trabalhados em diferentes salas de aulas pelo país, devem promover a produção do conhecimento histórico, fundamental para a formação intelectual, social e humana dos indivíduos, ao abordar cada um dos temas históricos em sala de aula, e aqui nossa ênfase é o trabalho com a história da África, dos africanos e da constituição da brasilidade, o professor de História traz consigo a formação da pesquisa que deve dar visibilidade ao processo de constituição dos saberes, como construções humanas e não no formato de processos acabados, “[...] Com isso, evita-se passar para o educando a falsa sensação de que os conhecimentos históricos existem de forma acabada, e assim são transmitidos.” (BEZERRA, 2010, p. 43).

Há um debate em torno da dicotomia entre ensino e pesquisa que dão a ideia de que o professor da educação básica é aquele profissional menor, cujo acesso ao conhecimento produzido é limitado e cuja participação na produção de conhecimento é inexistente, entretanto, consideramos que, para o desenvolvimento das atividades docentes o diálogo com a teoria permite ao professor/historiador um ampliação das possibilidades para que o ensino de história cumpra a função de dar sentido à disciplina que compõe seu métier.

Ao exercer a docência, depara-se cotidianamente com os questionamentos acerca da função desta área do conhecimento, questão que inclusive constituiu em ponto inicial das análises de Marc Bloch, na obra “Apologia da História ou o Ofício do Historiador” (2001), e ponto importante das análises de Karnal (2010) ao considerar que, quando nos indagamos acerca de nosso ofício, colocamo-nos frequentemente frente a questões como a que foi colocada por Shakespeare ao questionar: "Quem é Hécuba para eles, quem são eles para

\section{POLÊM!CA | Revista Eletronica da Ueij}


Hécuba" (KARNAL, 2010, p. 10). Ao docente de educação básica, diante desse questionamento, cabe a reflexão acerca de que,

[...] Em nosso contexto, esta frase equivale a indagar: qual a validade da História e do que eu faço para meu aluno e para mim? Como eu posso despertar no jovem tanto o interesse pela cultura mais formal como a capacidade e os instrumentos para analisar o mundo que o cerca? Talvez a pior pergunta seja a inversão desta: como eu vou descobrir qual a validade de tudo isso? Sim, porque é possível que o desânimo de um aluno seja apenas parte de um complexo maior que me inclua. (KARNAL, 2010, p. 10).

Dentre todas as peculiaridades da docência, o amadurecimento intelectual do professor é extremamente importante, ao permitir um diálogo possível com temporalidades e espacialidades distintas, o conhecimento, alcançável pela prática da pesquisa permite apreender, e possibilitar a compreensão de temporalidades e espacialidades, pois " [...] A primeira lição da experiência em sala de aula é que as fórmulas só servem quando são idealizadas numa aula estática" (KARNAL, 2010, p. 11), sendo assim, prescindir às fórmulas e propor alternativas é função do professor/pesquisador, cuja relação com o conhecimento e com a docência passa inclusive pelo amor com que este trabalho é desenvolvido em sala de aula.

\begin{abstract}
Quando eu era professor do que se chama hoje Ensino Fundamental, muitas vezes tinha que responder a essa pergunta para as crianças. Costumava brincar com os alunos da quinta série - a primeira série que tinha um professor específico para a disciplina História - devolvendo outra pergunta: "Por que vocês gostam tanto dos dinossauros?" Como eu, eles não sabiam a resposta, apenas diziam que gostavam dos dinossauros, que compravam aqueles bonecos e brincavam com eles. Claro, quando a gente gosta de algo, não pergunta porquê gosta, apenas gosta (a menos que a pessoa seja uma grande chata e fique regularmente questionando o que ama). (COSTA, 2008, p. 46).
\end{abstract}

Os argumentos até aqui apresentados permitem ao leitor perceber a defesa feita, de que o professor de história deve ser pesquisador, considerando que pesquisa e prática docente são indissociáveis e contribui para o enriquecimento dos métodos utilizados em sala de aula e que, "Que seja dito e repetido à exaustão: uma aula pode ser extremamente conservadora e ultrapassada contando com todos os mais modernos meios audiovisuais. Uma aula pode ser muito dinâmica e inovadora utilizando giz, professor e aluno.” (KARNAL, 2010, p. 09). Aos educadores deste novo milênio, coloca-se um desafio:

[...] adequar nosso olhar às exigências do mundo real sem sermos sugados pela onda neoliberal que parece estar empolgando corações e mentes. É preciso, nesse 
momento, mostrar que é possível desenvolver uma prática de ensino de História adequado aos novos tempos (e alunos): rica de conteúdo, socialmente responsável e sem ingenuidade ou nostalgia.

Historiador/professor sem utopia é cronista e, sem conteúdo, nem cronista pode ser. (PINSKY e BASSANEZI PINSKY, 2010, p. 190).

A prática de pesquisa permite ao professor se posicionar frente a debates com argumentos que possibilitem ao aluno entender que seres humanos em diferentes tempos históricos possuem visões de mundo diferenciadas. Cabem algumas reflexões frente a uma problemática recente em torno da obra de Monteiro Lobato "Caçadas de Pedrinho", em matéria publicada na Revista "Carta Capital”, intitulada "Caçada ao Racismo" (VIEIRA, 2012), o autor da matéria trata o julgamento da obra de Lobato como disseminadora de um "suposto racismo", o que pode levar a obra ser proibida entre os materiais didáticos. Esse tipo de postura frente à obra mencionada é resultante de uma negação de que as produções são fruto de certa temporalidade, o professor comprometido com a pesquisa terá condições de possibilitar ao aluno a compreensão dos contextos históricos e sociais em que a obra foi produzida.

Considerando que "Os conceitos históricos somente podem ser entendidos na sua historicidade. Isso quer dizer que os conceitos criados para explicar certas realidades históricas têm seu significado voltado para essas realidades, não sendo possível emprega-los indistintamente para toda e qualquer situação semelhante. ”(BEZERRA, 2010, p. 46).

A prática da pesquisa pode auxiliar no trato desta questão, entretanto alguns limites se colocam a esta:

É sabido que um grande número de professores de História não praticou a pesquisa em seus cursos de graduação (...). A maior parte dos cursos de graduação organiza a sua grade curricular com base na periodização tradicional da História, não incluindo nela a prática da pesquisa, isto sem contar com os cursos vagos existentes no país inteiro. Tal formação empurra o professor para os livros didáticos tradicionais, dando-lhe certeza no seu fazer. (JOANILHO, 1996, p. 11).

Ao tratar da pesquisa em sala de aula, Joanilho (1996, p. 12) aponta que os cursos de qualificação oferecidos para professores no estado de São Paulo colaboram na criação de verdadeiras "colchas de retalhos do conhecimento", não permitindo a relação entre os conteúdos trabalhados, o que deixa o professor angustiado "[...] podendo até levar a uma baixa estima sobre si próprio por não conseguir alinhavar tantos retalhos, mesmo porque não 
existe o desenvolvimento contínuo de determinado tema nos cursos [...]" (JOANILHO, 1996, p. 12).

Isto posto, ressalta-se que a qualificação docente deve primar pela prática da pesquisa, mediadora do trabalho em sala de aula, tornando possível a construção de saberes entre os alunos, pois o entesouramento do conhecimento não se constitui na repetição e acúmulo de informações, características do jornalismo. Na produção do saber histórico o tesouro do conhecimento é o resultado do acúmulo do conhecimento produzido, desta forma o conteúdo é de fundamental importância, sendo tantas vezes negligenciado no cotidiano escolar,

[...] o problema dos conteúdos e o tratamento teórico e metodológico que deveriam receber fazem com que essas proposições somente reforcem práticas disciplinares e de adestramento. A não explicitação teórico-metodológica lança uma cortina de fumaça sobre os conteúdos, enquanto o modo como a escola deve funcionar, o emprego do pessoal, a avaliação, o Plano Diretor e demais enquadramentos administrativos são tratados minuciosamente. (JOANILHO, 1996, p. 45).

Consideramos que o bom trabalho docente passa por um processo de amadurecimento intelectual, a proposta não é o trabalho teórico com alunos da educação básica, mas sim a prática teórica exercida pelo docente que permite o diálogo com diferentes conceitos historiográficos na elaboração de um saber escolar que prime pela qualidade.

\section{Historiador de ofício: a importância da prática de pesquisa no ofício do professor de história}

Tendo em mente que a dúvida é o ponto de partida para a busca do conhecimento, o historiador atento sabe que o processo de uma construção historiográfica perpassa inevitavelmente pelo diálogo em torno da questão temporal, considerando que "[...] a história impede que o atual seja vivido solitária e silenciosamente, em estado de amnésia. Ela restabelece o diálogo entre o presente e o passado, entre os homens mortos, que recuperam a vida, e os homens vivos, que reconhecem a morte [...]" (REIS, 2003, p. 109), essas questões também se apresentam ao professor da educação básica.

No processo de ensino e de aprendizagem as políticas educacionais que compõem o universo de atuação do docente, constituem-se em "[...] um processo permanente de enriquecimento dos conhecimentos, do saber-fazer, mas também e talvez em primeiro lugar, como uma via privilegiada de construção da própria pessoa, das relações entre indivíduos, grupos e nações." (DELORS et. al., 2010).

\section{POLÊM!CA | Revista Eletronica da Uej}


Tanto no trabalho com a pesquisa histórica, quanto com o desenvolvimento de atividades em sala de aula, o confronto com o documento é acompanhado de todo o espectro de mistérios vinculados às ideias do tempo presente e com interesses relacionados ao pesquisador. Não existe pesquisa histórica na qual o historiador se anula completamente como imaginavam e desejavam os positivistas do século XIX.

Sempre que se realiza uma pesquisa com levantamento de fontes primárias - aquelas fontes diretas e não as interpretações destas - faz-se necessário que se tenha em mente as circunstâncias em que estas foram produzidas, sua época, sua especificidade, sua função quando produzida, quem produziu e com qual intenção. O exercício de compreensão temporal, bem como das especificidades de cada tempo histórico, permitem que o profissional da educação básica tenha habilidade para tratar do processo de constituição da sociedade da qual ele e seus alunos fazem parte. É a compreensão das distinções temporais que tornam possível a prática do respeito às diferenças com as quais as pessoas se deparam cotidianamente no universo escolar.

Levando isso em consideração, o pesquisador está apto a estudar as fontes de uma forma menos superficial e mais crítica, podendo aprofundar-se no estudo das formas circunscritas e indiretas muitas vezes ignoradas à primeira vista, mas com as quais vários documentos do cotidiano na época analisada foram preenchidos.

Refletir sobre o discurso por meio do qual tempo e história se revestem de inteligibilidade, requer por parte do aprendiz de História um mergulho profundo e incessante nos textos produzidos pelos grandes nomes da historiografia. Desde Homero, Tucídides e Heródoto, passando pelos metódicos do século XIX, pelos marxistas influenciados pela obra de Marx e Engels, pela escola dos Annales fundada em 1929 tendo como principais mentores Marc Bloch e Lucien Febvre e ainda Braudel, Le Goff, Certeau, Foucault e tantos outros igualmente indispensáveis para uma boa formação intelectual de um historiador. Acerca das possibilidades desse diálogo em torno da historicidade, da construção historiográfica, Reis (2003) trabalha com a constituição da história como área de conhecimento, defendendo que houve uma ruptura entre a história e a filosofia iniciada no século XIX pela escola metódica (positivista) e prolongada até a atualidade por diversas correntes de pensamento histórico tais como o historicismo (Aron versus Dilthey), marxismo (Marx) e o programa dos Annales. Esta 
última coloca algumas questões ao ofício do historiador que continuam a incomodar os historiadores do século XXI e a motivar a prática constante da pesquisa.

Existem infinitas histórias a se contar e é possível que, por mais que as criemos e recriemos, o resultado não nos traga convicções. O peso do presente nas definições das formas, a partir das quais o passado será interrogado, nos leva a crer que a história e o historiador são objetos cujas transformações e mutações revelam uma inevitável imprevisibilidade, tornando impossível prever um futuro para o historiador, para o professor de história e para a historiografia. Essa compreensão passa pelas reflexões de Koselleck (2006) de que o futuro se constitui em “horizonte de expectativas", portanto não é previsível.

\section{O Ofício do Historiador e a Problematização do Passado}

Quer seja o ofício do historiador o domínio de métodos e técnicas circunscritos a um conjunto teórico ou, ainda, a um exercício de imaginação, a construção de uma narrativa verossímil, entre outras possíveis, não se pode negar que o surgimento da Escola dos Annales, uma concepção crítica às concepções históricas do século XIX, notadamente rejeitando a ênfase positivista e metódica em política, diplomacia e guerras, assim como a abordagem economicista do marxismo, inaugurou uma postura diferenciada.

Os representantes da corrente historiográfica, autointitulada Annales, propuseram-se a problematizar a história contrariando a coleção de fatos perpetuada por tendências anteriores, tentando se isentar de ideologia, embora esta tentativa seja passível de inúmeras críticas, já que o historiador, estando inserido em um tempo histórico, jamais conseguirá traçar uma análise imparcial.

A partir da problematização, os pesquisadores ligados aos estudos dos Annales desdobraram-se em várias linhas teóricas e campos de pesquisa, notadamente servindo de base para criar departamentos tanto de história social como econômica, fomentando debates acerca da natureza teórica do conhecimento histórico, atualmente incorporados ao panorama contemporâneo.

A problematização do passado deve levar em conta as possibilidades de interpretação deste passado, Reis (2003) estuda as diferentes constituições temporais ao longo da história, tratando desde as concepções metafísicas até a pós- modernidade, buscando definir a transição da modernidade para a pós-modernidade, para esse autor, "filosofia e história são atitudes

\section{POLÊM!CA | Revista Eletronica da Uerj}


complementares - toda pesquisa filosófica é inseparável da história da filosofia e da história dos homens e toda pesquisa histórica implica uma filosofia, porque o homem interroga o passado para nele encontrar respostas para as questões atuais” (REIS, 2003, p. 240).

Um debate instigante acerca da questão temporal, tão cara ao historiador/professor, também é proposto por esse autor:

\begin{abstract}
Seria possível segurar esse tempo humano que transcorre vertiginosamente, vivido na inquietação, no terror do horizonte mortal? Seria possível regular a clepsidra para que a areia/água não desça de uma só vez, sem deixar vestígios do ser que estava na parte superior? O mundo humano presente, que ocupa a parte superior da ampulheta, embora pareça sólido e eterno, tende a desabar sobre a parte inferior, e o que se torna visível, então, é um monte indiferenciado de areia, ser que foi e não é mais. (REIS, 2003, p. 181).
\end{abstract}

Pensar o tempo, a relação com a filosofia, as possibilidades de diálogo com a educação, eis a riqueza de variáveis dadas pela pesquisa e pelo trabalho com a teoria, que não podem ser algo prescindível no trabalho docente.

\title{
A Dinâmica dos Tempos Históricos e a Pesquisa no Campo da História
}

Inúmeros são os desafios da educação nestes tempos contemporâneos, as problemáticas postas à prática docente maximizam-se em um contexto de competição e desigualdade, no qual é imperativo a busca constante pela compreensão desse universo de saberes cada dia mais fragmentado. As transformações são inerentes ao campo de trabalho do historiador/professor de História, "Eu diria que ensinar História é uma atividade submetida a duas transformações permanentes: do objeto em si e da ação pedagógica. ” (KARNAL, 2010, p. 08).

A organização didática do trabalho realizado pelo historiador/professor é atravessada por uma historicidade, pelo conjunto de transformações pelas quais as sociedades humanas passaram ao longo do tempo e acabou atendendo às necessidades dos diferentes tempos históricos, exemplo disso foi a natureza artesanal da educação no momento em que ainda não vigorava a divisão social do trabalho.

A escola moderna viu nascer a divisão do trabalho voltada para a atividade de ensino, reflexos da produção manufatureira que necessitava de uma divisão do trabalho. Essas transformações se fizeram sentir na área da educação, provocando a compartimentação do

\section{POLÊM!CA | Revista Eletronica da Uej}


ensino e a consequente substituição do preceptor (erudito, no sentido de trabalhar com todas as áreas do conhecimento), pelo professor especializado, responsável por uma só disciplina.

A recorrência aos marcos temporais podem se inserir em reflexões de caráter mais conceitual como as propostas por Reis (2003), sobretudo quando pensa na possibilidade de um diálogo sui generis entre Ricoer, Koselleck e os Annales, tratando da forma como se formula o tempo histórico, que na concepção do autor se traduziria em um terceiro tempo, considerando o primeiro tempo apreendido pelo ser humano como sendo o da física, que se refere aos movimentos naturais, a um tempo exterior, supralunar, imortal. O segundo tempo seria o da filosofia, traduzido em mudanças vividas pela consciência, interior, sublunar, mortal, este seria o tempo da relação da alma consigo mesma. O tempo histórico seria o terceiro tempo traduzido pela relação entre natureza e consciência, entre o tempo físico e filosófico.

Para ajudar na compreensão deste terceiro tempo, Reis (2003) pensa a partir de duas perspectivas, a primeira fundamentada nas ideias de Ricoeur, cujas reflexões consideram os tempos, calendário, genealógico e arqueológico, para ele o historiador produz um terceiro tempo mediador entre o da natureza e da consciência. "O calendário pode ser considerado a primeira ponte que a história lança entre a natureza e a consciência, a segunda ponte é a sucessão de gerações". (REIS, 2003, p. 186). "Se o calendário é um conceito ponte astronômico- histórico, a geração é um conceito ponte biológico - histórico, para mediar esse diálogo e estabelecer o contato entre gerações o historiador precisa de uma terceira conexão entre o tempo da consciência e o natural, por isso recorre aos vestígios" (REIS, 2003, p. 188).

Outra perspectiva para ajudar a pensar na questão do tempo histórico seria de Koselleck (2006) , que trata da especificidade do tempo histórico, corroborando as reflexões feitas por Ricoeur, para o autor o tempo histórico está longe de ser resolvido pelo calendário e continua sendo a questão mais difícil posta pelo conhecimento histórico, suas reflexões levam em conta a importância do calendário para pensar o tempo histórico, o passado chega ao presente em ruínas e sua interpretação passa pela determinação da diferença entre passado e futuro, entre "campo de experiência" e "horizonte de espera" em um tempo presente. O futuro passado diz respeito a um futuro que se presentificou em determinado momento, é possível utilizar-se de alguns exemplos que ajudam a compreender a temática, desta maneira, 
no tempo europeu, anterior ao tempo medieval, a experiência impunha-se ao horizonte de espera, a concepção de história, portanto, seria a de mestre da vida.

O tempo cristão (escatológico) entende o futuro como a interrupção do passado, a escatologia e a própria história da cristandade e se traduz em um movimento cíclico de eterno retorno. O tempo moderno, cujos marcos para Koselleck são os anos de 1500 e 1800, foi o período da ampliação entre "campo de experiência" e "horizonte de expectativa", o signo seria a revolução, e a marca, a aceleração temporal, o tempo nesta concepção seria teleológico. Já o tempo do estado absolutista promoveria a ampliação do espaço de experiência, enquanto o tempo contemporâneo, pós-moderno, seria caracterizado pela desnaturalização do tempo e pela relativização, para Koselleck o conceito de pósmodernidade tem relação com a sociedade acelerada.

A perspectiva temporal trabalhada pelos Annales entende o tempo histórico como estrutural, o tempo social nesta perspectiva não é astronômico mesmo que se refira ao movimento dos astros, ele é cultural e tende à simultaneidade, sendo assim, o presente se liga ao passado e o passado ao presente de tal forma que o passado se torna presente e o presente se imuniza de tornar passado, a longa duração seria a tradução para a linguagem temporal dos historiadores.

A reflexão aqui empreendida acerca das perspectivas temporais e da constituição de um terceiro tempo a partir do olhar de Reis (2003), ajuda a compreender o ser humano neste tempo enquanto ser histórico, considerando que a história é mudança, o que permanece da experiência temporal é a compreensão da experiência vivida pelos seres humanos, para Reis (2003) a missão seria apreender o mundo dos homens através do estudo das suas experiências do passado, a nosso ver, experiências caríssimas ao professor de História.

\section{O Ofício do Historiador: olhares diversos}

Empreendemos a defesa pela pesquisa na prática docente, a ideia é pensar no profissional da educação como um historiador de ofício, neste sentido, “[...] Apreciaria que, entre os historiadores de profissão, os jovens em particular se habituassem a refletir sobre essas hesitações, esses perpétuos "arrependimentos" de nosso ofício. [...]” (BLOCH, 2001, p. 49).

\section{POLÊM!CA | Revista Eletronica da Ueij}


Perceber a importância da pesquisa passa pela compreensão das diversas possibilidades de acessar o conhecimento histórico, sendo assim: “[...] desbravado o caminho para a reconstituição da história como forma de atividade intelectual que é ao mesmo tempo poética, científica e filosófica em suas preocupações [...]” (WHITE, 1992, p. 15). O trabalho de problematização desse ofício leva a pensar que “[...] o historiador lida com uma temporalidade escoada, com o não visto, o não vivido, que só se torna possível acessar através de registros e sinais do passado que chegam até ele." (PESAVENTO, 2008, p. 42).

Valorizar a produção do conhecimento, por meio da pesquisa, equivale a propor por meio dos procedimentos de ensino histórico, uma realidade mais enriquecida em termos de possibilidades existenciais considerando que “(...) O homem que lê, que pensa, que espera, que se dedica à flânerie, pertence, do mesmo modo que o fumador de ópio, o sonhador e o ébrio, à galeria dos iluminados. E são iluminados mais profanos. Para não falar da mais terrível de todas as drogas - nós mesmos - que tomamos quando estamos sós. " (BENJAMIN, 1994, p. 33). O debate guiado por olhares historiográficos tão diversos, mas não excludentes, permite olhar para a riqueza de possiblidades criadas pela pesquisa,

[...] em nossos dias, as regiões onde é mais cerrada, onde os buracos negros se multiplicam, são as regiões da sexualidade e as da política: como se o discurso, longe de ser esse elemento transparente ou neutro no qual a sexualidade se desarma e a política se pacifica, fosse um dos lugares onde elas exercem, de modo privilegiado, alguns de seus mais temíveis poderes. Por mais que o discurso seja aparente bem pouca coisa, as interdições que o atingem revelam logo, rapidamente, sua ligação com o desejo e com o poder. [...]" (FOUCAULT, 2009, p. 9 -10).

A preocupação em ampliar o debate sobre a produção historiográfica e de sua boa utilização em sala de aula conduz à percepção de que, “[...] A história seria feita segundo ritmos diferentes e a tarefa do historiador seria, primordialmente, reconhecer tais ritmos. " (LE GOFF, 2003, p. 15). Não apenas de ritmos diferenciados, mas também de concepções distintas que esta disciplina foi constituída, analisando aquilo que nomeou de "paradigmas rivais", Cardoso (1997), distingue as concepções de história em torno da existência de dois paradigmas, um que chamou de "Iluminista ou Racional", que de acordo com sua interpretação abrangeria as propostas de escrita da história da escola metódica, do marxismo e da primeira e segunda geração da escola dos Annales, sendo que os pressupostos desse paradigma seriam a escrita de uma história pretensamente científica e racional, orientando-se por modelos macro históricos e teorizantes, buscando a inteligibilidade e a explicação. $\mathrm{O}$

\section{POLÊM!CA | Revista Eletronica da Uej}


outro paradigma de acordo com Cardoso (1997) seria o "Paradigma Pós Moderno", no qual estariam inseridos a terceira geração dos Annales, a Nova História, a História Cultural, a Micro História e o Pós Modernismo, cujos pressupostos seriam a existência de um niilismo intelectual, de um relativismo absoluto, um culturalismo relativista, no qual a História seria produzida na tríade: escrita, texto e leitura,

Em se tratando da escrita/produção, o historiador lança as perguntas sobre quem fala e de onde fala, ao enfocar o texto propriamente dito, o que se fala e como se fala e na análise da recepção, a questão jogada pelo historiador será discutir para quem se fala. (...). Se formos pensar as relações que se estabelecem entre o discurso e o real ou da representação com o seu referente -, vemos que elas podem se dar por aproximação com as figuras da literatura. (...) (PESAVENTO, 2008, p. 71).

Esta tríade mencionada por Cardoso e sistematizada por Pesavento constituiria o que Michel de Certeau (1982), nomeou de "Operação Historiográfica", que entendemos tratar-se do diálogo entre escrito, texto, leitura e ainda com as possibilidades metodológicas e conceituais para o trato com os mais diferentes objetos de pesquisa, neste caso, as reflexões em torno da utilização da metodologia da História Oral também compõe esta “Operação".

Embora estando normalmente ligada à História do Tempo Presente, a História Oral se destina ao estudo de períodos históricos variados. "O relato oral está, pois, na base da obtenção de toda a sorte de informações e antecede a outras técnicas de obtenção e conservação do saber "[...] a escrita, quando inventada, não foi mais do que uma nova cristalização do relato oral” (QUEIROZ, 1988, p. 16). A oralidade está ligada aos processos iniciais de transmissão do conhecimento, ao fazer a introdução geral da "História Geral da África”, Joseph Ki-Zerbo (2010) alerta que o trato com as fontes para o estudo da África não é fácil, estando organizadas em três pilares do conhecimento histórico daquele continente: os documentos escritos, a arqueologia e a tradição oral, sendo a última caracterizada pelo autor como uma espécie do "Fio de Ariadne", por meio do qual o pesquisador vai percorrendo os labirintos que permitem escrever uma história contada por velhos “[...] de cabelos brancos, voz cansada e memória um pouco obscura, rotulados às vezes de teimosos e meticulosos [...]" (KI-ZERBO, 2010, p. 37-38). As questões metodológicas apontadas por Ki-Zerbo dialogam com a problemática da pesquisa histórica enquanto constituindo o material com o qual o professor de História se relaciona cotidianamente e que permite ao aluno refletir sobre a historicidade dos processos que envolvem os seres humanos e a si próprios enquanto sujeito desta história.

\section{POLÊM!CA | Revista Eletronica da Ueij}




\title{
Pesquisa Histórica e Estudo da África
}

Em uma aula de História, ministrada a alunos do Ensino Médio, ao lançar o questionamento “o que sabem a respeito da África?”, o professor foi surpreendido com uma resposta dada quase em uníssono “A África é um país pobre”. A frase pronunciada por alunos quase completando a etapa básica de ensino, dá visibilidade a uma importante questão, a de que o continente africano se apresenta para uma parcela bastante significativa da população brasileira como algo totalmente desconhecido, ou ainda sob o prisma de ideias estereotipadas, nas quais o continente africano é visto ou sob a lógica de um mundo exótico, ou sendo composto por um aglomerado de pessoas vivendo em condições sub-humanas.

Nos últimos anos algumas ações têm sido aplicadas ao ensino, buscando minimizar este desconhecimento, um exemplo dessas ações foi a criação de leis que tornam obrigatório o ensino da História e da cultura africana e indígena nos currículos escolares (é o caso da Lei $10.639 / 2003)^{1}$, entretanto estas medidas apresentam um caráter paliativo e pouco eficiente, caso consideremos o reduzido número de aulas de história no currículo da educação básica, o que não deve impedir que as ações de pesquisa histórica neste campo fortaleça a busca do conhecimento do passado de uma parcela bastante significativa da população brasileira.

O tema da diversidade africana dialoga com aquilo que Edgar Morin intitula como "Os sete saberes necessários à educação do futuro", dentre eles, destaca-se a complexidade,

\begin{abstract}
O conhecimento pertinente deve enfrentar a complexidade. Complexus significa o que foi tecido junto; de fato, há complexidade quando elementos diferentes são inseparáveis constitutivos do todo (como o econômico, o político, o sociológico, o psicológico, o afetivo, o mitológico), e há um tecido interdependente, interativo e inter-retroativo entre o objeto de conhecimento e seu contexto, as partes e o todo, o todo e as partes, as partes entre si. Por isso, a complexidade é a união entre a unidade e a multiplicidade. Os desenvolvimentos próprios a nossa era planetária nos confrontam cada vez mais e de maneira cada vez mais inelutável com os desafios da complexidade. (MORIN, 2000, p. 38).
\end{abstract}

Pensar acerca da África passa pela concepção de que o estudo de sua diversidade permite ao pesquisador/professor o contato com a complexidade na qual aquele espaço foi

\footnotetext{
${ }^{1}$ Lei 10.639, de 9 de janeiro de 2003, que altera a Lei de Diretrizes e Bases da Educação Nacional (9.394/96) e inclui no currículo oficial da Rede de Ensino a obrigatoriedade da temática "História e Cultura Afro-Brasileira" e dá outras providências, substituída Lei 11.645/2008 que regulamente a obrigatoriedade do Ensino da História e Cultura Afro-brasileira e amplia as exigências para a inserção da etnia indígena em todos os níveis de Ensino (BRASIL, 2003).
} 
sendo configurado ao longo do tempo. Dentre a amplitude de questões que envolvem o estudo da África é fundamental que se discuta os processos de formação levando em conta os aspectos inerentes aos povos localizados ao Norte do continente, cujos contatos distintos com outros povos, dentre eles os islamizados, os distingue das populações localizadas na porção subsaariana que estabeleceram contatos diferenciados ao longo da história.

Uma das propostas para o diálogo com esta complexidade que constitui a África foi realizado por Muryatan Barbosa (2012) em estudo que compõe o banco de teses da USP, intitulado "A África por ela mesma: a perspectiva intra africana na História Geral da África (HGA)". A referida tese busca nos artigos da obra HGA, publicados pela UNESCO em vários idiomas entre eles a língua portuguesa, argumentos que permitam a defesa de que há necessidade da produção de uma história da África produzida por africanos e que pense o processo de constituição da diversidade africana, partindo dos elementos da própria cultura africana.

Dentre os questionamentos feitos por Ki-Zerbo, editor e autor de artigos na HGA, pesquisa que vem sendo produzida desde 1970, está o de que a cultura oral africana não foi aceita ao longo do tempo como fonte para o estudo daquele continente, enquanto que os poemas Ilíada e Odisseia, atribuídos a Homero, são reconhecidos como fonte para o estudo da Europa. "Com efeito, havia uma recusa a considerar o povo africano como o criador de culturas originais que floresceram e se perpetuaram, através dos séculos, por vias que lhes são próprias e que o historiador só pode apreender renunciando a certos preconceitos e renovando seu método." (M'BOW, 2010, p. 26).

No prefácio da obra o diretor da UNESCO refere-se à pouca importância histórica que havia sido dada ao estudo do continente,

Da mesma forma, o continente africano quase nunca era considerado como uma
entidade histórica. Em contrário, enfatizava-se tudo o que pudesse reforçar a ideia de
uma cisão que teria existido, desde sempre, entre uma "África branca" e uma
"África negra" que se ignoravam reciprocamente. Apresentava-se frequentemente o
Saara como um espaço impenetrável que tornaria impossíveis misturas entre etnias e
povos, bem como trocas de bens, crenças, hábitos e ideias entre as sociedades
constituídas de um lado e de outro do deserto. Traçavam-se fronteiras
intransponíveis entre as civilizações do antigo Egito e da Núbia e aquelas dos povos
subsaarianos. (M'BOW, 2010, p. XXII).

A perspectiva intra africana, proposta pela HGA e debatida por Barbosa (2012), dialoga com importante obra de referência, "Orientalismo: o Oriente como invenção do 
Ocidente" na qual Said recorre ao argumento de que a construção historiográfica acerca do Oriente, em geral traduz o olhar do ocidental sobre o Oriente. A perspectiva intra africana propõe uma história de si, da constituição de seu território, da flutuação de sua população, da diversidade de suas práticas e de seus comportamentos, a partir do olhar daquele que viveu as experiências, negando assim que o olhar acerca de si não seja estereotipado pela tradução do outro.

Para Said "a análise do texto orientalista, enfatiza a evidência, que de modo algum é invisível, de tais representações como 'representações', e não como descrições naturais do Oriente. " (1990, p. 32). Neste aspecto cabe salientar que o trabalho do historiador não seria fabricar, produzir um objeto, mas um trabalho de representação por meio da prática da observação, mediada pelo amadurecimento teórico e aliado às práticas dos atores sociais que ocupam um determinado espaço, tendo em conta suas vivências, experiências e memórias, juntamente com certas condições materiais que permitiram se organizarem de determinadas formas.

As trajetórias revividas pelas memórias que trazem à tona e que são ferramentas fundamentais para o trabalho do historiador são experiências de todos aqueles homens e mulheres e não grupos minoritários, que participaram da construção de todos os processos históricos.

A busca pela experiência dos sujeitos que constroem, cotidianamente, histórias que se cruzam, interpenetram e moldam as sociedades, são perseguidas pelo historiador, cujo papel de acordo com Said (1990, p.33), orienta-se pela representação do passado dessas sociedades, por meio do trabalho de pesquisa, desta forma: “[...] Em qualquer exemplo, pelo menos da linguagem escrita, não existe nada do gênero de uma presença recebida, mas sim uma represença, ou uma representação." (SAID, 1990, p. 33). Neste sentido, as produções no campo da historiografia são representações de quem escreve, a partir do universo daquele que escreve. Essas são questões que nos parecem ser extremamente importantes àquele que se dedica à tarefa de reconstruir o passado histórico por meio da pesquisa que culmina em saber histórico em sala de aula.

A opção teórica por determinados conceitos é sempre pensada, tendo em vista um universo de possibilidades, que normalmente são negligenciados, pela problemática do tempo para a realização da pesquisa e também pela incompatibilidade de determinados conceitos

\section{POLÊM!CA | Revista Eletronica da Uerj}


dentro de um projeto que se intenta trabalhar. De toda a miríade conceitual imprescindível ao trabalho do historiador/professor está o conceito de tempo. A dinâmica temporal concernente ao estudo da diversidade africana pode ser possível a partir do trato com este conceito, tão caro ao pesquisador do campo da história e permite o diálogo entre momentos distintos, no intuito de compreender como vão se constituindo as especificidades da relação entre seres humanos e espaço. A narrativa acerca da História da África permite que o historiador recorra a tempos bastante diversos daquele escolhido como recorte temporal da pesquisa, na intenção de dialogar com os mecanismos de constituição da realidade.

A concepção de uma história magistral vitae não é o que buscam os historiadores contemporâneos, Koselleck dedicou-se a explicação do conceito apontando que Cícero, ao se referir a modelos helenísticos, teria cunhado o emprego da expressão, sendo assim, pertenceria ao campo da erudição, uma das tarefas desse modelo de escrita de história como mestre da vida seria "[...] testemunha dos tempos, a luz da verdade, a vida da memória, a mensageira da velhice, por cuja voz nada é recomendada senão a imortalidade do orador." (KOSELLECK, 2006, p. 43).

$\mathrm{O}$ autor recorre à explicação desse topo, desta concepção histórica que teria predominado até a historiografia do século XIX, para enfim defender a diversidade de tempos históricos que se relacionam, argumentando que o passado se apresenta como o campo de experiência, enquanto o futuro seria o universo de expectativa humana, nesta relação entre passado e futuro é que a história se constitui, nela impera uma diversidade de tempos históricos,

\begin{abstract}
Se a velha história [Historie] foi arrancada de sua cátedra, e, certamente, não apenas pelos iluministas, a quem tanto aprazia servir-se de seus ensinamentos, isso aconteceu na esteira de um movimento que organizou de maneira nova a relação entre passado e futuro. Foi finalmente "a história em si" [die Geschitchte selbst] que começou a abrir um novo espaço de experiência. A nova história [Geschichte] adquiriu uma qualidade temporal própria. Diferentes tempos e períodos de experiência, passíveis de alternância, tomaram o lugar outrora reservado ao passado entendido como exemplo. (KOSELLECK, 2006, p. 47).
\end{abstract}

Ao recorrermos às reflexões de Koselleck sobre o tempo histórico, nosso objetivo é pensar essa dinâmica de tempos múltiplos que convergem em certos momentos. No tocante a pesquisa acerca da História da África, essa relação temporal apresenta-se como válida para a análise de uma gama de recortes temporais. O estudo da historicidade dos povos africanos é atravessado por problemáticas inerentes ao campo da experiência histórica, o passado na 
perspectiva Koselleckniana, entendido como campo de experiência, dialoga com propostas, como as da Lei 10.639/2003 (BRASIL, 2003), ao buscar dar visibilidade à História e à diversidade da África e dos africanos, contribuem para o fortalecimento do universo das experiências que constitui a África e as complexas relações humanas ao longo do tempo, experiências fundamentais na constituição do Brasil.

A complexidade que envolve tal estudo pode ser lida, por exemplo, na imagem do africano pelos portugueses antes dos contatos, cuja representação da África, em particular do negro, são alvo de visões de mundo marcadas pelo etnocentrismo. Os referentes culturais europeus que caracterizam a imagem do negro anterior aos séculos XV e XVI são traduzidos, por exemplo, nas Cantigas de Santa Maria, que remontam ao século XIII,

Nas Cantigas de Santa Maria, uma obra de meados do século XIII, o adjectivo (sic.)
negral é mesmo sinónimo (sic.) de desgraçado. A cor negra é também a cor do
castigo dos maus ou pecadores por oposição à cor branca, da recompensa dos bons,
como no Boosco Deleitoso. A contraposição branco/negro de sentidos
respectivamente positivo e negativo não representa em si qualquer preconceito de
tipo racial, mas é taõ-só o resultado do sistema de cores próprio do código cultural.
(...) O diabo intervém sob a forma animal - cavalo negro, ave de cabeça negra, etc. -
e principalmente sob a forma humana ou semelhante. Toma a aparência de uma
criança negra no Espelho dos Reis de Álvaro Pais [...] (HORTA, 1991, p. 45)

Pensando no propósito deste artigo, ou seja, a importância da pesquisa no universo da prática docente, ressalta-se que é imprescindível a utilização das fontes para o estudo da representação do negro feita pelo europeu, a sondagem em diversas áreas da produção escrita em que tal representação pode ser lida, apresenta-se sob fontes narrativas que contribuem para reforçar estereótipos em relação ao africano, "estereótipo do diabo negro, atormentador ou tentador, que continuava no século XIV e até meados do século XV (pelo menos na iconografia) a ter grande sucesso no Ocidente cristão.” (HORTA, 1991, p. 46).

Dentre as fontes escritas portuguesa e de versão portuguesa está o Libro del Conoscimiento, escrito por um franciscano espanhol em meados do século XIV,

[...] cheguei a uma grande cidade que dizem Graciona, que é cabeça do império de Abdeselib que quer dizer servo da cruz, e este Abdeselib é defensor da igreja de Núbia e Etiópia e este defende o Preste João que é patriarca de Núbia e Etiópia, e senhoreia mui grandes terras e muitas cidades de cristãos mas que são negros como a pez e queima-se com fogo em sinal de cruz em reconhecimento de baptismo, e como quer que estas gentes são negros, mas são homens de bom entendimento e de bom siso, e têm saberes e ciências, e têm terra muito abundante de todos os bens porque há muitas águas e boas das que saiem (sic.) do paraíso terreal. (LIBRO DEL CONOSCIMIENTO apud HORTA, 1991, p. 53).

\section{POLÊM!CA | Revista Eletronica da Uej}


Nota-se que, mais determinante que a cor negra da pele, pode revelar-se a apreciação que é feita do africano quanto a sua religião, entre outras leituras possíveis - como a relação clima/caracterização psicológica -, a passagem em destaque do Libro del Conoscimiento, mostra como pode ser diferente a imagem do negro cristão.

Outra perspectiva para a pesquisa em História da África que pode contribuir para o ensino de História, diz respeito às teorias raciais e à produção literária no Brasil, faremos algumas considerações acerca do século XIX e o debate envolvendo o racismo realizado no Brasil. As práticas racistas podem ser entendidas como ideologia que teve grande repercussão no Brasil, especialmente após a divulgação do "Ensaio sobre a desigualdade da raça humana", escrita por Joseph-Arthur Gabineau, em 1853, cujas críticas formuladas por Tocqueville,

\footnotetext{
O determinismo e pessimismo raciais de Gobineau sofreram a crítica de Alexis de Tocqueville (1805-1859), que apontou a insensatez de acreditar que a ação humana seja puro fruto biológico do sangue e da raça, sem espaço para a liberdade e a escolha moral. No entanto, a obra de Gobineau fez grande sucesso na Alemanha, onde toda uma linhagem de intelectuais foi muito influenciada por suas teorias raciais, destacando entre eles Richard Wagner (1813-1883) e Friedrich Nietzsche (1844-1900). (TAMANO et. al., 2011, p. 758).
}

A obra de Gobineau também influenciou a produção intelectual no Brasil sendo "essencial para entender como a ideologia das teorias racistas pode ter sido útil para ajudar o país a conservar a escravidão por tanto tempo". (TAMANO et. al., 2011, p. 758). As teorias raciais que ganharam força no pensamento dos intelectuais brasileiros do século XIX foram criadas na Europa, no momento considerado o ápice do chamado racismo científico, "essas teorias foram a máxima do chamado darwinismo social” (PAES, 1992, p. 161 apud TAMANO et. al., p. 759).

A produção literária também é relevante na pesquisa histórica considerando que "[...] A literatura parte de um real que pretende dizer, falha sempre ao dizê-lo, mas ao falhar diz outra coisa, desvenda um mundo mais real do que aquele que pretendia dizer. " (PERRONEMOISÉS, 1990, p. 102 apud TAMANO et. al., 2011, p. 162). Um exemplo da produção literária que pode ajudar no diálogo temporal inerente ao estudo da História e tão cara ao professor/historiador no sentido de ampliar o universo do conhecimento do aluno com o qual trabalha, é a leitura das obras literárias. Tamano et. al. (2011), dedicam-se a entender duas obras literárias, "O Cortiço" e "Canaã", como expressões de teorias raciais. A mudança por

\section{POLÊM!CA | Revista Eletronica da Uej}


que passam Romão e o seu cortiço é paralela a mudanças sentidas no país. O Brasil para se fazer moderno e civilizado, tornava-se um viveiro de obras, alterava a sua estrutura urbana, adquiria novos hábitos, rejeitando o seu passado colonial e imperial. A nação reclamando uma higienização mental e corporal afastava para os arrabaldes e morros as classes pobres.

A guinada do século XIX para o XX foi marcada por uma irrupção de ideias e conflitos em solo brasileiro, permeados de aspectos científicos, tecnológicos e ideológicos. No cerne desse momento histórico estavam as teorias raciais, que buscavam compreender o país e suas mazelas sociais por meio de explicações biológicas. Em todas as atribuições de papéis conforme o tipo racial apelava-se para a autoridade da ciência, ou melhor, dos que se pretendiam conhecedores de ciências da época, fossem as teorias antropológicas ou da eugenia - enfim, para um cientificismo erigido, em geral, com base pouco científica sob ralas camadas de um verniz, mas habilidosos em atribuir a si o estatuto de verdade e atrair o interesse das camadas letradas do país.

\section{Considerações Finais}

Parte-se do pressuposto de que há uma dicotomia entre docência e pesquisa, que deve ser repensada no ensino superior, visto que o profissional da educação básica deve ter habilidades para o trabalho de relacionar a construção temporal, resultante do trabalho historiográfico, com o cotidiano dos alunos sob sua orientação.

A questão que se coloca é de que o acesso ao conhecimento produzido pelos seres humanos no tempo é possível por meio da pesquisa, desta forma, nossa defesa é pela universidade que forme o pesquisador/professor, que não encerre sua aula em um instrumento único de trabalho, o livro didático, que consiga prescindir ao material que lhe é fornecido, enriquecendo-o, relacionando-o com outras possibilidades. Que seja capaz de pensar acerca das suas aulas, não transformando estas em mera reprodução, que não se intimide frente aos desafios impostos pela educação e a entenda como emancipadora de seres humanos, emancipação possível pelo acesso ao conhecimento.

Entende-se que a dinâmica das escolas muitas vezes é castradora, entretanto, é notório que um ensino de história maçante e reprodutor apenas reforça esta realidade, valorizar a pesquisa como constituinte da prática docente na educação básica é um caminho interessante para pensar novos horizontes para o ensino em nosso país.

\section{POLÊM!CA | Revista Eletronica da Uerj}


No tocante ao ensino da África, para além da legislação que versa a respeito de sua obrigatoriedade, cabe ao professor no cotidiano da sala de aula, criar os mecanismos para o trabalho com tal temática, este artigo propôs algumas alternativas, entende-se a possibilidade de abordagem da temática de formas bastante variáveis, seja pela documentação produzida pela UNESCO, organizada em uma riquíssima coletânea de textos, recorrendo às produções narrativas do século XIII, ou ainda promovendo trabalho interdisciplinar com a literatura, a sugestão do referencial literário é apenas uma, dentre muitas outras possíveis. Reforça-se a necessidade que está colocada para a graduação em História de primar pela formação de pesquisador/professor, se assim o for as fontes para o trabalho com a História da África em sala de aula serão problematizadas no âmbito escolar enriquecendo o universo histórico e cultural dos alunos do ensino básico do país.

\section{Referências}

BARBOSA, Muryatan Santana. A África por ela mesma: a perspectiva africana na História Geral da África (UNESCO). São Paulo: USP, 2012. Mimeo.

BENJAMIN, Walter. Obras Escolhidas: magia e técnica, arte e política. Tradução Sérgio Paulo Rouanet. 7.ed. São Paulo: Brasiliense, 1994.

BITTENCOURT, Circe Maria Fernandes. Ensino de História: fundamentos e métodos. 4.ed.São Paulo: Cortez, 2011.

BEZERRA, Holien Gonçalves. Ensino de História: conteúdos e conceitos básicos. In: KARNAL, Leandro (org.). História na sala de aula: conceitos, práticas e propostas. 6.ed. São Paulo: Contexto, 2010

BLOCH, Marc. Apologia da história ou o ofício de historiador. Tradução André Telles. Rio de Janeiro: Jorge Zahar Ed., 2001.

BRASIL. Lei 9.394, de 20 de Dezembro de 1996. Estabelece as diretrizes e bases da educação nacional. Diário Oficial da República, Brasília, DF, 23 dez. 1996.

BRASIL. Lei nº 10.639, de 09 de Janeiro de 2003. Diário Oficial da República, Brasília, DF, 10 jan. 2003.

BRASIL. Lei 11.645, de 10 de Março de 2008. Diário Oficial da República, Brasília, DF, 11 março 2008.

CABRINI, Conceição, et al. Ensino de história: revisão urgente. São Paulo: EDUC, 2000.

CARDOSO, Ciro Flamarion; VAINFAS, Ronaldo. Domínios da História: ensaios de teoria e metodologia. 5. Ed. Rio de Janeiro: Editora Campus, 1997.

CARDOSO, Ciro Flamarion. Um Historiador Fala de Teoria e Metodologia: ensaios. Bauru, São Paulo: Edusc, 2005.

CERTEAU, Michel de. A Escrita da História. Rio de Janeiro: Forense Universitária, 1982.

\section{POLÊM!CA | Revista Eletronica da Uej}


COSTA, Ricardo da. Para que serve a História? Para nada... In: SINAIS - Revista Eletrônica. Ciências Sociais. Vitória: CCHN, UFES, Edição n.03, v.1, Junho. 2008. pp.43-70.

DELORS, Jacques et al. Educação Um Tesouro a Descobrir: relatório para a UNESCO da comissão internacional sobre a educação para o século XXI. Brasília, julho de 2010.

FONSECA, Selva Guimarães. Caminhos da História Ensinada. 3. ed. Campinas, SP: Papirus, 1995.

FOUCAULT, Michel. A Ordem do Discurso. Tradução Laura Fraga de Almeida Sampaio.19. ed. São Paulo: edições Loyola, 2009.

HORTA, José da Silva; et. al. A imagem do africano pelos portugueses antes dos contatos. In: O Confronto do olhar: o encontro dos povos na época das navegações portuguesas - séculos XV e XVI. Coordenação de António Luís Ferronha. Lisboa: Editorial Caminho, 1991.

JOANILHO, André Luiz. História e prática: a pesquisa em sala de aula. São Paulo: Mercado de Letras, 1996.

KARNAL, Leandro. A história moderna e a sala de aula. In: (org.). História na sala de aula: conceitos, práticas e propostas. 6.ed. São Paulo: Contexto, 2010.

KI-ZERBO, Joseph (Editor). História Geral da África (Vol. I). 2. Ed. Rev. Brasília: UNESCO, 2010.

KOSELLECK, Reinhardt. Futuro Passado: contribuição à semântica dos tempos históricos. Rio de Janeiro: Ed. PUC Rio/Contratempo, 2006.

LE GOFF, Jacques. História e Memória. Tradução Bernardo Leitão, et. al.. 5 ed. Campinas, SP: Editora da Unicamp, 2003.

M'Bow, M. Amadou Mahtar. Prefácio. In: KI-ZERBO, Joseph (Ed.). História Geral da África I: Metodologia e Pré-História da África. 2. Ed. Rev. Brasília: UNESCO, 2010.

MORIN, Edgar. Os sete saberes necessários à educação do futuro. Tradução de Catarina Eleonora F. da Silva e Jeanne Sawaya. 2. Ed. São Paulo: Cortez; Brasília, DF: UNESCO, 2000.

PESAVENTO, Sandra Jatahy. História \& História Cultural. 2. ed. Belo Horizonte: Autêntica, 2008.

PINSKY, Jaime \& BASSANEZI PINSKY, Carla. Por uma história prazerosa e consequente. In: KARNAL, Leandro (org.). História na sala de aula: conceitos, práticas e propostas. 6.ed. São Paulo: Contexto, 2010.

QUEIROZ, Maria Isaura Pereira de. Relatos Orais: do "indizível" ao "dizível". In: SIMSON, Olga de Moraes Von. Experimentos com Histórias de Vida (Itália-Brasil). São Paulo: Vértice, 1988.

REIS, José Carlos. História \& Teoria: historicismo, modernidade, temporalidade e verdade. Rio de Janeiro: Editora FGV, 2003.

SAID, Edward W. Orientalismo: o Oriente como invenção do Ocidente. Tradução de Tomás Rosa Bueno. São Paulo: Companhia das Letras, 1990.

TAMANO, Luana Tieko Omena; SANTOS, Poliana dos; MAGALHÃES, Gildo; MARTINS, Ana Claudia Aymoré. O Cientificismo das teorias raciais em O cortiço e Canaã. História, Ciências, Saúde, Manguinhos, Rio de Janeiro, v. 18, n. 3, jul-set. 2011.

\section{POLÊM!CA | Revista Eletronica da Ueri}


VIEIRA, Willian. Caçada ao Racismo. Revista Carta Capital. Setembro/2012. Disponível em: http://www.cartacapital.com.br/sociedade/cacada-ao-racismo-2/. Acesso em: 02/10/2012.

WHITE, Hayden. Meta História: a imaginação histórica do século XIX. Tradução de José Laurênio de Melo. São Paulo: Editora da USP, 1992.

Recebido em: 20/05/2015.

Aceito em: 14/07/2015. 